\title{
Las virtudes cívicas em la formación de mediadores
}

\section{As virtudes cívicas na formação dos mediadores}

\author{
Elsa Zurita ${ }^{l}$
}

Karla Sáenz_2

\section{RESUMEM:}

El tema de estudio que se aborda en este artículo son las principales virtudes que el mediador debe desarrollar en el proceso de mediación transformativa para favorecer la restauración de las partes. Entendiendo que el desarrollo de virtudes debe ser aprendido por los mediadores de manera formal para el desarrollo de la mediación con enfoque colaborativo y de desarrollo personal.

\section{PALABRAS CLAVE:}

Virtud, Mediador, Habilidad.

\section{RESUMO:}

O objeto de estudo abordado neste artigo são as principais virtudes que o mediador deve desenvolver no processo de mediação transformadora para favorecer a restauração das partes. Entendendo que o desenvolvimento das virtudes deve ser aprendido pelos mediadores de maneira formal para o desenvolvimento da mediação com uma abordagem colaborativa e desenvolvimento pessoal.

\section{PALAVRAS-CHAVE:}

Virtude, Mediador, Habilidade.

\footnotetext{
${ }^{1}$ Alumna del doctorado en Métodos Alternos de Solución de Conflictos de la Facultad de Derecho y Criminología de la Universidad Autónoma de Nuevo León. elsa.zuritahr@uanl.edu.mx.

2 Doctora en Ciencia Política. Investigadora Nivel 1 del Sistema Nacional de Investigadores del Consejo Nacional de Ciencia y Tecnología. Catedrática de la Facultad de Contaduría Pública y Administración de la Universidad Autónoma de Nuevo León. karla.saenzlp@uanl.edu.mx.
} 


\section{INTRODUCCIÓN}

Es necesario entender el concepto de virtud en sí, desde el enfoque de la filosofía, la psicología y posteriormente pasar al enfoque social, como también recordar los diferentes conceptos como valor, capacidad, habilidad y competencia, señalando así, que si bien estas son importantes y tomadas en cuenta en los perfiles de los profesionales, también hay otras herramientas que contribuyen al desarrollo del mismo como son las virtudes, es por eso que se explicaran, en diferentes áreas del conocimiento y cuál es el enfoque desde las Ciencias Sociales como las virtudes cívicas, aprendiendo así, en que radican, como se componen de forma cognitiva y motivacional y como esta contribuye desde el enfoque interno y desde el enfoque colectivo, su relevancia y participación en los Mecanismos Alternativos de Solución de Controversias, y finalmente la relación que estos mecanismos tienen con la prudencia, paciencia, tolerancia y templanza en una mediación transformativa, con la finalidad de tener una mayor comprensión sobre como desarrollarlas, y como pueden aportar al perfil profesional del mediador de forma personal, favoreciendo a la restauración de las partes que intervienen en los procesos de mediación y aportando a la sociedad de forma positiva.

\section{LAS VIRTUDES DESDE EL ENFOQUE DE LA FILOSOFÍA}

Se comenzará explicando el termino desde el enfoque filosófico, el cual nos dice que su significado en latín con el término virtud se deriva de virtus-itis, fortaleza de carácter, vigor el término virtud tiene un antecedente remoto originado en el griego: Areté, Aristón, el superlativo de bueno-agathon. Fue utilizado como sinónimo de excelencia, pero aplicable también a animales, cosas y a divinidades (Vidal Gual, 2006), se explica el origen griego y se pone de manifiesto la importancia de desarrollar las virtudes en cada individuo y que estos sean conscientes de que son las virtudes e identificar cuales se tienen y cuáles están ausentes. 
Es hasta Sócrates que el término se refiere más específicamente a la excelencia moral humana, a un saber acerca del bien que puede ser comunicado mediante la enseñanza (Rodriguez Luño, 2001).

Sócrates identificaba la virtud con el conocimiento: no se puede hacer lo justo si no se le conoce. Para este autor lo único que hace falta para hacer a las personas virtuosas es enseñarles en que consiste la virtud verdadera.

Para Platón, la felicidad en esta vida está aunada a la práctica de la virtud y al cultivo de la Filosofía. Así la virtud es armonía, salud del alma, medida metrón, proporción symetría y purificación, represión de las pasiones que permite ser libre para contemplar las ideas. Considera que hay cuatro virtudes fundamentales: prudencia, justicia, fortaleza y templanza (Sanabria, 1984). Se pone de manifiesta que desde mucho tiempo atrás nos indican la importancia de las virtudes e indican que como desarrollarlas nos permite desarrollarnos internamente y esto beneficia forma colectiva.

Hay diversos tipos de virtudes que corresponden a las dos partes del alma: a la irracional, la fortaleza andreia, la templanza sofrosyne, la justicia dike-dikaios y la prudencia. Al alma racional corresponden la sabiduría sofía, la ciencia episteme, el entendimiento intuitivo, la prudencia frónesis y el arte tekné (Sanabria, 1984)

Para Aristóteles existían virtudes y vicios y las virtudes que el propone son la sabiduría, la templanza, la continencia, la justicia, la libertad y la magnanimidad, este autor definía a estas virtudes como la excelencia no es una acción, es un hábito. En Ética a Nicómaco, Aristóteles expone que la virtud humana no es una facultad, sino un hábito: surge como consecuencia de la práctica y el aprendizaje. (Naranjo Boza, 2004)

Aristóteles distingue dos tipos de virtud humana. Una virtud moral, que rige acciones y emociones, es un rasgo del carácter adquirido mediante el hábito, implica la elección y se realiza de acuerdo a la recta razón. Otra, virtud intelectual, rige el pensamiento, viene de la enseñanza y se ejerce tanto en el juicio práctico como en la contemplación teórica. (Burlando, 2012), podemos decir que las virtudes morales cambian de acuerdo en el contexto en el que se desarrollen y son regidas por las emociones, es decir no son estáticas a diferencia de las intelectuales que son adquiridas de acuerdo al pensamiento consciente, es decir, que cada 
individuo las desarrolla y aprende conscientemente, para después aplicar criterios de comportamiento apropiado.

Un ejemplo para lo antes mencionado lo dice en el Libro VII de la Política, Aristóteles examina los diversos tipos de gobierno, por ejemplo, que el gobierno de hombres libres es más noble y conforme a la virtud que el gobierno despótico (ARISTÓTELES, Política, VII, 1333b) y considera la cuestión de cuál es, el mejor modo de vida, para individuos y ciudades. Aquí hallamos su doctrina política capital relacionada a la educación y la cultura, vale decir: que cada tipo de gobierno depende de ciudadanos dotados de virtudes que se relacionan con las necesidades y propósitos del gobierno (Burlando, 2012), pero si el individuo no es consciente de las virtudes y no las interioriza como podrán saber no tendrán la oportunidad de conocerse así mismo si no también no verán el enfoque de las necesidades que requieren las instituciones a las que presten servicios y por ende no podrán identificar que virtudes necesitan los que acuden en busca de esos servicios.

Para Santo Tomás de Aquino, la virtud moral puede existir, ciertamente, sin algunas de las virtudes intelectuales, como la sabiduría, la ciencia y el arte; pero no puede existir sin el entendimiento y la prudencia. No puede darse virtud moral alguna sin la prudencia, porque la virtud moral es un hábito electivo, es decir, que hace buena la elección, para lo cual se requieren dos cosas: primera, que exista la debida intención del fin, y esto se debe a la virtud moral que inclina la facultad apetitiva al bien conveniente según razón, y tal es el fin debido; segunda, que el hombre escoja rectamente los medios conducentes al fin, lo cual no se verifica sino por la razón en el uso correcto del consejo, del juicio y del imperio, cual hacen la prudencia y las virtudes anejas a la misma, según queda dicho (q.57 a.5.6). Luego la virtud moral no puede existir sin la prudencia. (Echegoyen Olleta, 2005).

\section{LAS VIRTUDES DESDE EL ENFOQUE SOCIAL - PSICOLÓGICO.}


"La virtud se define como la fortaleza moral de la voluntad de un hombre en el cumplimiento de su deber, una coerción moral de su propia razón legisladora, en la medida en que esta se constituye a sí misma como poder ejecutivo de la ley, es el actuar congruente con la moral y el deber ser" (Kant, 1993).

Pellegrino, conceptualiza a la virtud como la que nos hace funcionar bien como seres humanos y alcanzar nuestros propósitos haciéndonos buenos seres humanos (Pellegrino \& Thomasma, 1993)

López de Llergo, concluye cuáles son las características generales de las virtudes, Además las clasifica en intelectuales las que perfeccionan la inteligencia le pertenecen: la sabiduría, la ciencia, la inteligencia, la sindéresis, la prudencia y el arte y las morales las que se apoyan en la especulación y provocan la acción, mejorando el hacer y consecuentemente el ser, influyen en la inteligencia y permiten alcanzar la bondad, la prudencia, la justicia, la fortaleza y la templanza (López de Llergo, 2000).

De acuerdo a la definición de virtudes se mencionarán cuatro características de las virtudes que apoyan al desarrollo del perfil del mediador:

1. Enriquecer la naturaleza de quien las adquiere.

2. Arraigan los valores que ya se tienen, los que se desarrollan y los que se adquieren.

3. Perfeccionan al ser humano.

4. Solo se dan en el ser humano racional.

En la Psicología Positiva cuando se usa el término virtudes generalmente se establece una especie de clasificación jerárquica de los rasgos positivos:

Primer Nivel: Virtudes. Son características valoradas a nivel social, filosófico y religioso. Casi siempre se trata de rasgos que se remontan a los inicios históricos de muchas civilizaciones. Por ejemplo, sabiduría, templanza, valentía.

Segundo Nivel: Fortalezas. Componentes psicológicos (es decir, mecanismos o procesos) que en conjunto definen a las virtudes; vienen a ser como las rutas a (o modos hacia) la expresión de una virtud. Las fortalezas son rasgos sujetos a diferencias individuales, aunque 
en sí mismas se definen como universales. Por ejemplo, la fortaleza del amor al aprendizaje forma la base para el eventual desarrollo de la sabiduría.

Tercer Nivel: Temas situacionales. Son hábitos o prácticas que sólo tienen sentido en un contexto específico, y que llevan a la expresión de una fortaleza. Por ejemplo, la inclusividad (la tendencia a hacer que los demás se sientan parte de nuestro propio grupo) es un tema situacional que lleva a expresar una fortaleza: la amabilidad, la cual a su vez es una de las formas en que la virtud de la humanidad se manifiesta.

Con las diferencias conceptuales que se han observado acerca de las virtudes se podría definir como aquel hábito por elección es perfeccionando y que tiene un propósito moral impulsado por la razón y que en su actuar siempre radique hacer el bien y este favorezca intrapersonal e interpersonal, una persona que posea virtudes será capaz de actuar correctamente en todos los escenarios que se le presenten.

Diferenciación de virtud, valor. Capacidad, habilidad y competencia.

Es necesario diferenciar conceptos como virtud, valor, capacidad, habilidad y competencia ya que serán mencionados en los siguientes párrafos y medida que estas se entiendan se podrá comprender la diferencia de virtud y valor, ya que muchas ocasiones estas suelen confundirse, sin quitar el mérito de cada uno y esclarecer los demás conceptos.

Tabla 1. Diferenciación de conceptos.

\begin{tabular}{|l|l|}
\hline Virtud & $\begin{array}{l}\text { Es una acción positiva que nos permite conducirnos bajo principios morales } \\
\text { y valores orientados hacia una conducta excelente, estas son inherentes o se } \\
\text { van adquiriendo están orientados hacia una conducta positiva, nos ayudan a } \\
\text { diferenciar lo bueno de lo malo y enaltecen los valores de cada individuo. }\end{array}$ \\
\hline Valor & $\begin{array}{l}\text { Están orientados al crecimiento personal por un convencimiento intelectual } \\
\text { son bienes que la inteligencia del hombre conoce acepta y vive, como algo } \\
\text { bueno para el como persona, pero estos son ambiguos y se desarrollan de } \\
\text { acuerdo a su entorno. }\end{array}$ \\
\hline Capacidad & Son los recursos que tiene cada individuo para desempeñar una tarea. \\
\hline Habilidad & Es la destreza con la que una persona puede llevar una tarea con éxito. \\
\hline
\end{tabular}


Competencia Capacidades humanas que constan de diferentes conocimientos, para llevar a cabo una actividad a través de los conocimientos específicos adquiridos.

Fuente: Elaboración propia.

No solo es necesario el conocimiento científico-técnico, si no el acercamiento a la humanidad. En esta aproximación no basta la competencia profesional, sino las disposiciones necesarias para ser una buena persona, un buen profesional (Moreno Villares, 2014).

Ahora bien, entendiendo que los valores son ambiguos, es decir, lo que una persona puede considerar como algo valioso, para otra puede ser completamente lo contrario a diferencia de las virtudes que, al ser de carácter universal, demuestran que la virtud en un individuo lo será para el otro de igual manera.

En este sentido el Programa de capacitación integral que se refiere a el perfil especialista de la secretaria de gobernación, en su contenido nos data de puntos referentes a la ética profesional del mediador y de cómo la ética profesional del mediador en conjunto con las virtudes y valores sirven de guía para la conducta en los procesos en los cual este participe.

En el apartado de ética profesional de este programa, se define proveniente del latín ethicus que significa forma de ser o carácter, como conjunto de conocimientos derivados de la investigación de la conducta humana al tratar de explicar las reglas morales de manera racional, fundamentada, científica y teórica. Es una reflexión sobre la moral. La ética está relacionada con el estudio de los valores morales que guían el comportamiento humano en la sociedad. En un sentido práctico, el propósito de la ética y la moral es muy similar. Ambas son responsables de la construcción de la base que guiará la conducta del hombre, determinando su carácter, su altruismo y sus virtudes, además de enseñar la mejor manera de actuar y comportarse en sociedad. La ética, tienen por objeto establecer la conducta que deben de regir el personal involucrado.

Se debe plantear la diferencia entre valor y virtud y como desarrollarlas y culturizar su uso puede generar un impacto en el perfil del mediador, los mediadores deben tener una conducta de excelencia en el desempeño de su labor, por lo tanto, al usar las virtudes no solo de desarrollará en ámbito profesional también contribuirán en el ámbito personal. 
De acuerdo al Programa de capacitación integral los principios y valores éticos en el desempeño profesional es la tarea más ardua en la transformación en el sistema procesal que conlleva al cambio cultural con respecto a conductas en el desempeño de la responsabilidad. Los Mediadores, Conciliadores, Facilitadores, Jueces, Magistrados, Fiscales, Defensores, Peritos, Policías, Universidades y la sociedad en general, pueden contribuir en la formación de individuos que sean capaces de lograr una metamorfosis cultural en el cambio de la cultura ética. En este sentido, la filosofía y la sociología jurídica deben ponderar los valores éticos de los hombres y mujeres útiles a la realidad nacional; es por esto que no necesariamente a la mediación por ser del orden jurídico se le debe de dar solo ese enfoque, es importante que debido a la naturaleza humana que esta tiene y los puntos tan vulnerables que trata con los seres humanos se desarrolle un enfoque humanista que dote a los mediadores no solo de las herramientas pedagógicas y reglamentarias necesarias para desarrollar su labor, también que se les enseñe la importancia de desarrollar virtudes aportando al sentido humano en pro de su profesión

El aspecto ético- moral es de importancia relevante en el proceso de formación integral de las personas, ya que de ello dependerá su desarrollo, considerado como la base fundamental de la superación personal y social.

Es así como programa de capacitación integral del mediador en sus párrafos remarca la importancia de seguir desarrollando herramientas en el mediador que no solo lo hagan un buen profesional, sino que también este sea excelente y lo que marque la diferencia sea ese aspecto moral, ético y virtuoso.

Por otro lado, Código de Ética del Centro de Litigación y Mediación de la Facultad de Derecho y Criminología de la Universidad Autónoma de Nuevo León nos menciona el significado de la ética como la palabra ethos que es costumbre, hábito, conducta, carácter y que la ética original hablaba más de hábitos y actitudes que de actos.

De acuerdo al a este código se pueden encontrar párrafos referentes a la conducta ética del mediador y trasladar a las virtudes atestiguando la importancia concedida a las mismas en la práctica profesional atreves de conductas éticas personales y profesionales por lo cual se mencionan ejemplos que se identifican en los siguientes textos: 
- El mediador deberá observa una conducta ética en el desempeño de su función, la cual deberá constituirse con el cumplimiento desde un ámbito personal y profesional, aplicando los principios rectores de la Mediación, tales como respetar la voluntariedad de las partes, confidencialidad, neutralidad, imparcialidad, equidad y honestidad.

- El mediador debe respetar las providencias que tomen las partes, con plena libertad de voluntariedad para someter el procedimiento de mediación, y la información que contribuyan para el desarrollo de dicho proceso e implicando el respeto que se tiene que dar a las partes, con la premisa que lleguen a un acuerdo libre y voluntario, o en su caso, si así lo desean dar por terminada dicha mediación en cualquier etapa del procedimiento, por lo que el prestador del servicio deberá respetar la decisión de los participantes.

- El prestador de servicio deberá observar una actitud receptiva, de escucha activa y de respeto hacia la información que revelen las partes, para la guarda y reserva de la información que confíen, siendo intransferible a un tercero, inclusive las sesiones de carácter privada, y no deberá externar la información recabada a la parte contraria, salvo que cuente con su expresa autorización para hacerlo y que esto facilite a dicho procedimiento.

- La neutralidad es un ideal que debe mantener el prestador de servicio en su actuar, a efecto de mantenerse ajeno a los intereses que sustenten las diversas partes del conflicto.

- El mediador debe ser imparcial, principio de una conducta y actitud abierta al diálogo, el cual se forja con un lenguaje adecuado y transparente entre los participantes, de acuerdo a las circunstancias, vivencias sociales, culturales y educativas, el cual incite al razonamiento en su total disposición.

- El medidor deberá procurar siempre entender las necesidades físicas y mentales de los involucrados en el conflicto con objeto de procurar que el desarrollo de las sesiones del procedimiento sea de un tiempo prudente, en las cuales se debe evitar a toda costa el estrés, creando un ambiente de confianza, cordialidad y armonía, logrando acuerdos y en lo posible excelentes términos.

- El mediador tendrá la capacidad de enfrentar situaciones adversas, deberá actuar con fortaleza y también resistirse a las influencias, actuar con rectitud y valentía para poder cumplir con su función en el desempeño de sus actividades como prestador de servicio profesional. 
"La actividad mediadora en el país ha trascendido y evolucionado al coadyuvar a la impartición de justicia, la confianza de la ciudadanía es evidente pero es necesario fortalecer y estar atento a la ética del mediador" explica (Steel Garza, 2015). En este sentido las virtudes contribuyen a fortalecer la ética del mediador aportando más opciones de conductas.

El reto para la mediación implica que los servidores públicos y profesionales que se dediquen a esto no solo cuenten con las herramientas técnicas y específicas, lo que suma al profesional es el desarrollo de una ética profesional, de valores, cualidades, virtudes y buenas actitudes de comportamiento humano que permitan un mejor desarrollo en su profesión, teniendo como valor agregado el desarrollo humanista al cual no se le da la importancia que requiere.

\section{ÉTICA, MORAL Y DEONTOLOGÍA.}

Si bien el objetivo principal de este capitulado es la deontología del profesional de la mediación, es necesario establecer las diferentes distinciones semánticas entre ética, moral y deontología, para poder llegar a un análisis profundo y entender las diferencias entre estas, aunque en principio puedan parecer lo mismo, por tanto, se empezará analizando el concepto de ética y como este a evolucionando en el tiempo y de acuerdo al contexto social en el que se desarrolla, para posterior mente analizar la diferencia entre ética y moral y comprender cuál es la función de la deontología como parte de la ética pero de forma específica.

\section{ÉTICA}

Desde que los hombres viven en sociedad, ha sido necesario contar con regulaciones morales del comportamiento en pro del bienestar colectivo, tal como señala (Aranguren, 2013) es importante señalar que algunas de estas pautas se establecían de forma arbitraria, ya sean de manera religiosa, hábitos o costumbres que eran de acuerdo a cada lugar y contexto de la 
sociedad, o leyes impuestas por líderes para prevenir descontrol en el actuar de los individuos en sociedad.

Para este apartado es necesario entender la ética desde el punto de vista global y como esta ha ido evolucionando a lo largo de la historia, cuáles son sus diferentes enfoques de acuerdo al contexto que se vivía e inclusive conocer cuál era la concepción de la misma para los filósofos que han sido importantes en la historia, por tal motivo se hará un análisis de esta en diferentes puntos en el tiempo, para su mayor comprensión.

Los términos de ética y moral (ethos y mos moris), provienen de los griegos y de los romanos en donde ambos identificaban estas palabras con el sentido de la palabra costumbre y formaban parte de las ciencias deontológicas, las cuales estudian a los seres humanos como deben ser ( Ramos Montes, 2018). Definir conceptualmente la ética resulta complejo ya que a lo largo de la historia y en todo el mundo se ha tratado de definirla y explicarla, es por eso que para este apartado su significado y su comprensión deberán ser sencillos, debido a la gran importancia que tiene en la vida humana y su conexión con la naturaleza de la misma. Es necesario saber que el significado de la ética ha evolucionado y ha tenido diferentes interpretaciones en donde se aprecian particulares puntos de vista de diversas corrientes e interpretaciones y puede variar considerando el contexto social y la época para definir la ética.

Las palabras ética y moral tienen un significado etimológico semejante en sus raíces griega y latina. En el uso común se emplean casi siempre indistintamente, se comenzará explicando que el término de la palabra ética que se “deriva de la palabra griega 'ethos' que significa costumbre y vendría a designar el conjunto de costumbres buenas, convertidas en normas obligatorias para el ciudadano de bien en su comportamiento diario. Esas normas equivaldrían a los criterios para juzgar si las conductas de las personas son correctas. También se les suele llamar normas morales ya que la palabra moral proviene de la latina 'mos' ('mores' en plural), traducción de la palabra griega ethos”. (Ortiz Millán, 2016)

Para Sócrates, indica (Rodríguez, 1998), la ética como parte de la educación es aquello que constituye la virtud, puede conseguir que la gente sea y actúe conforme a la moral; pensaba que toda persona tiene conocimiento pleno de la verdad última contenida dentro del alma y sólo necesita ser estimulada por reflejos conscientes para darse cuenta de ella. Su crítica de la injusticia en la sociedad ateniense, le costó su procesamiento y una sentencia de muerte, al 
parecer por corromper a la juventud de Atenas, de acuerdo al pensamiento de Sócrates todos podemos actuar conforme al bien alcanzando un nivel de consciencia que nos lo permita, pero este solo se alcanza con los buenos actos que sean practicados día a día para que esto se vuelva como parte natural de nuestro actuar diario, en la mediación la ley de mecanismos es la herramienta que le da al mediador las pautas de cómo debe actuar y esto solo se puede dar a través de la educación.

Según Platón (428 a.C), citado por (García, 1980),el bien es un elemento esencial de la realidad. El mal no existe en sí mismo, si no como reflejo imperfecto de lo real, que es el bien; pero el contexto y la realidad en la que vivimos hoy en día referente a la enseñanza de valores y la ética hace más difícil que los adolescentes los practiquen, vivimos en una realidad en la cual cada vez se están perdiendo los valores y si no se practican nuestra realidad estará muy alejada del bien, es importante que el mediador se conduzca con principios y actuar bien en todo momento.

Aristóteles (384 a.C), discípulo de Platón, consideraba que el bien supremo del hombre es la felicidad, que consiste en la plenitud de su realización como tal, y que no consiste en los placeres, sino en la producción, creación, y en la actitud práctica social, la política. En su principal obra sobre esta materia, "Ética Nicómaco" (IVa.C.), definió la felicidad como una actividad que concuerda con la naturaleza específica de la humanidad; el placer acompaña a esta actividad, pero no es su fin primordial", el mediador puede alcanzar esta felicidad tal como lo describía Aristóteles, no solo se prepara profesionalmente y alcanza la autorrealización, además usa este conocimiento en pro de la sociedad y su creatividad al momento de estar en una mediación, el punto clave de este capitulado también es dejar claro que no estamos muy alejados de lo que pensaban hace miles de años otros filósofos, pero recalcar que es necesario que estas ideologías no sean olvidadas.

Para los siglos IV y III a.C., ( García D. , 1980) “el filósofo materialista griego Epicuro (322a.C.) desarrolló un sistema de pensamiento, que identificaba la bondad más elevada con el placer, sobre todo el placer intelectual, al igual que el estoicismo, abogó por una vida moderada, incluso incorruptible, dedicada a la contemplación. Mantenían posponer el placer inmediato con el objeto de alcanzar una satisfacción más segura y duradera en el futuro", por lo tanto, insistieron en que la vida buena lo es en cuanto se halla regulada por la autodisciplina, en este 
sentido el mediador tras dirigirse en principios éticos en el día a día en su profesión logra que con la práctica se conviertan en profesionales incorruptibles elevando su ética deontológica y a su vez convirtiéndoles en mejores personas.

Del siglo Val XI, plantea (Campos, 1988) "hay como un vacío en las historias de las ideas. Fueron épocas de ocupaciones, asentamiento de los invasores en el imperio Romano, formación de un nuevo conocimiento con la asimilación de la cultura antigua de Roma. Se fundaron las primeras universidades: Oxford, Cambridge, Paris, Cracovia, entre otras. La ética estaba fundamentada en el acatamiento del estudio de las escrituras sagradas, había que aprendérselas al pie de la letra, memorísticamente", en este punto de la historia y debido al contexto la sociedad debía actuar de acuerdo a lo que la religión establecía y aunque sus métodos no eran aceptados por todos, la gran mayoría actuaba de acuerdo a aquellos criterios.

Posteriormente, el dominio de los principios religiosos, como pautas éticas durante la escolástica, a mediados del siglo XI hasta el siglo XV, señala (Rodríguez; Lozano, 1998), se fortalecieron con Tomás de Aquino quien recoge todo el saber de sus tiempos, pero adaptándolos a sus dogmas religiosos, en las que sus doctrinas se han adecuado al desarrollo de la ciencia contemporánea, por supuesto, sin desprenderse de su fundamentación idealista religiosa,

A medida que la Iglesia medieval se hizo más poderosa, se desarrolló un modelo de ética que aportaba el castigo para el pecado y la recompensa de la inmortalidad para premiar la virtud. Las bondades más importantes serán la humildad, la continencia, la benevolencia y la obediencia; la espiritualidad, o la bondad de espíritu, era indispensable para la moral. Todas las acciones, tanto las buenas como las malas, fueron clasificadas por la Iglesia y se instauró un sistema de penitencia temporal como expiación de los pecados. Durante el renacimiento, la influencia de las creencias y prácticas éticas cristianas disminuyeron, pero el ser humano debe aspirar más que a comportamientos condicionados de premio y castigo, la aspiración máxima del ser en el sentido de actuar con bondad en los actos y en beneficio de otros, dejando atrás el pensamiento egoísta y esto solo podrá ser alcanzado, si los valores se comienzan a enseñar e interiorizar desde la educación, pero no por imposición, si no como parte de nuestra naturaleza.

La Reforma protestante provocó un retorno general a los principios básicos dentro de la tradición cristiana, cambiando el énfasis puesto en algunas ideas e introduciendo otras nuevas. 
Al cristiano se le exige una conducta moral o la realización de actos buenos, pero la justificación, o la salvación, viene sólo por la fe. Posteriormente, durante la Reforma la responsabilidad individual se consideró más importante que la obediencia a la autoridad o a la tradición y ya para el siglo XX, se asumen las teorías del existencialismo, en la que predomina el interés por la elección ética individual, está claro que el concepto de ética individual hace más complicado al momento de entenderlo de forma colectiva y tener el propio concepto y actuar de acuerdo a lo que cada individuo aprende al día a día es correcto, pero no se debe olvidar que aplicar criterios para situaciones específicas es necesario por tanto la deontología del mediador permite actuar bajo estos principios.

Sin embargo, cabe destacar la posición de algunos filósofos modernos que no aceptan ninguna de las religiones tradicionales, el filósofo alemán (Fernández , 2002) mantenía que no existe ningún Dios, aunque alguno puede surgir en el futuro. Los seres humanos, por lo tanto, se hallan solos en el Universo y tienen que adoptar y asumir sus decisiones éticas en la conciencia constante de la muerte, si bien cada individuo debe actuar y tomar decisiones consientes estas no deberían tener relación con la muerte ya que este es un hecho innegable y condicionar una conducta por esto no sería actuar del todo de forma consciente y con ética.

El filósofo y escritor francés Jean-Paul Sartre tal como lo cita (Filgueiras Nodar, 2017) razonó su agnosticismo, resaltó la heideggeriana conciencia de la muerte. Sartre mantuvo que los individuos tienen la responsabilidad ética de comprometerse en las actividades sociales y políticas de su tiempo. El supuesto conflicto sobre la existencia de un Dios omni presente, no revestía ningún sentido de trascendencia para el individuo, pues en nada afectaba a su compromiso con la libertad personal, en este sentido el mediador no solo se realiza como ser humano, también colabora de forma social para construir una mejor convivencia y esto se ve reflejado a través de los acuerdos que se logran en una mediación.

Entre otros filósofos modernos, como el estadounidense (Dewey, 1899), figuran los que se han interesado por el pensamiento ético desde el punto de vista del instrumentalismo, el bien es aquello que ha sido elegido después de reflexionar tanto sobre el medio como sobre las probables consecuencias de llevar a cabo ese acto considerado bueno o un bien.

La discusión contemporánea sobre la ética ha continuado con los escritos de (Moore, 2002), quien señala que los principios éticos son definibles en los términos de la palabra bueno, 
considerando que 'la bondad' es indefinible. Esto es así porque la bondad es una cualidad simple, no analizable, es aquí cuando se pone de manifiesto que la ética tiene que ver con el sentido humano que es imprescindible y que no debemos olvidar, no solo son pautas de conductas a través de las cuales el mediador debe conducirse de están de forma reglamentaria, son principios que están estratégicamente escogidos para que el comportamiento del mediador funcione de forma correcta, pero sin descuidar el sentido humano.

Por otro lado, (Cortina, 1999) señala, "la ética como aquella parte de la filosofía que se dedica a la reflexión sobre lo moral", y como un tipo de saber que intenta construirse racionalmente, utilizando para ello, el rigor conceptual y los métodos de análisis y explicación propios de la filosofía. Como reflexión sobre las cuestiones morales, la ética pretende desplegar los conceptos y argumentos que permitan comprender la dimensión moral de la persona humana. En cuanto a la dimensión moral, sin reducirla a sus componentes psicológicos, sociológicos, económicos o de cualquier otro tipo, la ética no ignora que tales factores condicionan de hecho el mundo moral, si bien es importante tener una ética propia personal, en este sentido la individualidad no debe de dejar de lado lo colectivo, porque es lo que le permite al individuo trascender de forma social y ayudar a mejorar su entorno.

Otro autor como (Bilbeny, 1992), indica que "la ética propone el estudio de un cierto tipo de acción humana normativa a la que se llama acción moral y el objeto es averiguar la validez de sus preceptos y privilegios". De su concepto hace algunas aclaratorias, entre las cuales plantea: la "normativa no debe aceptarse en el sentido de meramente reglado reglamentada", de esa clase de acción se ocupan ya, por ejemplo, las ciencias jurídicas o la psicología social. La acción normativa que atañe al filósofo moral, es aquella cuyos principios y preceptos constituyen los únicos móviles de esta acción normativa que merece en exclusiva el calificativo de moral.

Así mismo, se presenta la definición propuesta por (Hartmann, 2011); la cual plantea una definición descripción de la ética en estos términos señalando que "es un conocimiento práctico, no sólo conoce el bien donde se encuentre, y en caso de darse, aconseja cómo producirlo por medio de las obras, o cómo evitar que se le pongan obstáculos", lo primero que hace este autor es definir el término, puesto que en la ética se han dado muchos puntos de vista y ello debe llevar a encontrar la existencia de algún punto común, Este doble plano está 
orientado con la mirada puesta en el bien como algo excelente en sí y con la mirada puesta en que es recto o bueno en la práctica, muestra que el elemento común a toda ética implica directamente una diferencia entre el ser del bien y su realización práctica, en este caso el mediador no solo conoce los principios, también los practica y en actuar aspira a tener una conducta excelente, pero es necesario señalar que es complicado que se encuentre un punto en común en la ética ya que ella involucra diferentes factores ya sean territoriales o culturales y depende mucho del contexto en que se desenvuelva, por tanto encontrar un punto en común resulta complicado por la complejidad de los factores que en ella intervienen.

La ética, nos da la pauta sobre cómo cada individuo puede comportarse reflexionando sobre el bien y el mal en cada acto, si estas acciones se convierten en un hábito podemos hablar de virtud, en el ámbito académico y filosófico y en conjunto con otras definiciones propuestas, este término suele referirse a la moral y esta engloba distintos códigos morales de acuerdo a los contextos, situaciones, lugares y cultura, hacer esta distinción resulta útil porque se deben considerar los enfoques individuales y colectivos y entender que engloba la ética colectiva.

No sólo se habla de ética sino de diversos tipos de la misma (ética normativa, ética aplicada, matemática, empírica, filosófica, utilitarista, religiosa, profesional, científica, judicial, bioética, etc.). (Pantoja Vargas, 2011), por ello en este apartado se explicara este significado porque se busca entender la relación conceptual necesaria para poder asociar el sentido de la deontología en el contexto de la mediación, tema de este capitulado.

Entender la ética desde diferentes enfoques teóricos no implica que esta se aleje de la práctica, pues en esta se debe poner mayor énfasis para poder entenderla y usarla en el día a día del profesional, no basta el conocimiento científico, el profesional debe contar con herramientas humanas que le permitan llevar su práctica de mejor manera y lo más humano posible y es ahí donde se debe poner especial atención a la hora de estar preparando profesionales no solo de la mediación sino de otras ramas del conocimiento, no se debe de perder el sentido humano y de valores.

La ética es visualizada como una de las ramas más importantes de la filosofía. Está ligada estrechamente con conceptos como la moral, la cual es considerada su sinónimo, los valores y la cultura principalmente. Se destaca al momento de tomar decisiones porque "tiene que ver con el proceder de los hombres en relación a su conciencia y responsabilidad" (Gurria 
Dibella, 1996), es por ello que la ética como tal tiene gran peso en el mediador porque con su conocimiento se dirige su actuar en los proceso, sabiendo que este está ejerciendo su profesión de la mejor manera posible de acuerdo a criterios que son específicos para el área de conocimiento y la práctica que los mediadores realizan.

(Parker Green, 2001) “opina que la ética es el uso de las herramientas de la razón para generar reglas que guíen el juicio en circunstancias tanto generales como particulares. Con ello se obtendrá una mayor visión y una amplia gama de alternativas a escoger para encontrar el mejor camino hacia el bien persona y común", es por eso que estas pueden aportar al perfil profesional del mediador y favorecer a el proceso de la mediación ya que no solo estas aportan al proceso si no también dan la seguridad y confianza a los mediados que hacen uso de estos mecanismos se está actuando de la mejor manera posible, bajo códigos que son conocidos y respetados por los profesionales de la mediación.

Para englobar todo lo anterior, (Fischer \& Orme, 2003), "mencionan que la ética debe estar basada en estructuras, políticas y códigos o en un entendimiento general de las reglas. Aunque igualmente, es necesario contar con individuos que puedan diferenciar entre lo que está bien y mal, que sean capaces de tomar decisiones difíciles y suficientemente firmes para apegarse a ellas”, para que el mediador tenga actué desde un punto de vista normativo en la mediación debe tener claras estas directrices por medio de su propio código deontológico, proporcionándole autonomía y dejando fuera las confusiones que pudieran surgir con figuras a fines. Esto se logra cuando la mediación tiene su propio conjunto de principios y reglas que marcan el comportamiento que determina esta actividad profesional, pero es importante señalar que el solo tenerlas no es suficiente ya que el mediador deberá conocerlas e interiorizarlas de forma consiente para que en esta actividad no quepan dudas ni para ellos ni para los mediados.

Los antes mencionado plantea si existe semejanza entre la ética y la moral, por lo cual se hace esta comparación entre ética y moral que está sujeta de acuerdo a las costumbres según los grupos sociales y su desarrollo cultural, históricamente la reflexión sobre la ética ha formado parte de la filosofía y esta ciencia es la que nos conduce a la definición esencial de la ética, o sea, la reflexión sobre la fundamentación de la moral o principios, valores y normas de comportamiento que dan deontología y código deontológico del mediador tercera época sentido a la vida humana o, más sencillamente, la teoría o ciencia del comportamiento moral 
categorizándolo en bueno-malo, correcto-incorrecto, obligatorio-libre, por lo cual es importante tener en cuenta lo que nos dice (Lindsay, 2009) la ética consiste en una reflexión sobre los actos humanos realizados libremente por la persona en cuanto a su dimensión de bondad o maldad, proporcionando las razones del por qué la conducta humana es correcta o incorrecta, con esta definición se puede decir que la ética es universal y esta define el comportamiento de cualquier persona, de acuerdo a su ubicación geográfica, etnia y religión, pero las profesionales además de incluir valores universales, ayudan a diferenciar lo que está bien de lo que está mal, lo correcto de lo incorrecto del comportamiento humano, es decir la conducta de cada profesional, con esto queda claro que la tarea principal del mediador es actuar con apego a las normativas ya establecidas, que lo convierten en un buen profesional, dejando una autorrealización por ejercer bien su profesión y trayendo como consecuencia la construcción de mejores relaciones que están sustentadas en armonía, paz y respeto, por mencionar algunos beneficios, teniendo en cuenta que son una gran cantidad de ellos los que pueden adquirir las personas que acuden en busca de estas alternativas, la ética es la herramienta que ayuda a el profesional a actuar con principios claros que le permiten ejercer mejor su profesión.

Entendemos aquí la Ética como una rama de la Filosofía que reflexiona sobre la moralidad, es decir, como "Filosofía moral". Ahora bien, la moralidad es un fenómeno muy complejo, y por ello la propia definición de la misma es objeto de controversia filosófica en la cual se hablará en el próximo apartado de forma más específica. Por ejemplo: para (Bentham, Un fragmento sobre el gobierno., 2010) "los filósofos utilitaristas, la moralidad es cuestión de cálculo acerca de las posibles consecuencias de los comportamientos disponibles en un momento dado, bajo el imperativo de elegir entre ellos aquel comportamiento que sea más favorable para el mayor número de seres dotados de la capacidad de gozar y de sufrir”, por tanto este pensamiento es la base de la conciencia moral del utilitarismo es este principio de utilidad, que trata de alcanzar la famosa "mayor felicidad para el mayor número de personas". La mayor cantidad posible de placeres para el individuo y su comunidad. De esta forma, las cualidades, definidas empíricamente, pueden ser aprobadas o rechazadas según su tendencia a aumentar, o no, la felicidad. Hemos, por tanto, de empezar calculando el valor de todos los placeres y dolores probables que una acción puede causar, atendiendo a su intensidad, duración, certidumbre, etc. Y después de eso, observar qué se impone para decidir si una acción es buena o mala, analizando este concepto a profundidad si bien este tiene como objetivo alcanzar el 
bienestar para el mayor número de personas en el contexto especifico de la mediación este no sería un enfoque viable debido a que esta ética es temporal en un momento especifico del tiempo y el mediador actuaria de acuerdo a la situación que se le presente y de acuerdo a las circunstancias que se le presenten y con las herramientas éticas que considere en ese lapso de tiempo, por tanto la ética que se requiere para esta profesión es una que no sea temporal pero que tenga la flexibilidad de cambiar de acuerdo a contextos que se puedan derivar de esta ciencia.

En cambio, para los filósofos de inspiración deontolinista la moralidad no es sólo una cuestión de cálculo, aunque siempre hay que prever las consecuencias de los posibles cursos de acción, sino que hay límites a dicho cálculo en no dañar inmerecidamente a las personas, que son los únicos seres dotados de dignidad (no precio), ni siquiera en el caso hipotético de que el daño inmerecido infligido a una sola persona pudiera redundar en beneficio de la mayoría de seres capaces de sufrir. Así pues, la Ética es una disciplina normativa, puesto que no describe lo que ocurre de hecho en el mundo, sino que trata de orientar indirectamente la acción humana argumentando sobre la mejor manera de entender la moralidad (Cortina \& Martínez, 1996). De modo que, según se entienda la moralidad de una manera o de otra, los principios y las normas que han de orientar el comportamiento pueden ser diferentes en algunos casos, aunque en la mayor parte de ellos es muy probable que dos éticas diferentes recomienden el mismo comportamiento.

\section{LA MORAL EN LA FORMACIÓN DEL MEDIADOR}

He afirmado antes que dada la coincidencia semántica entre 'ethos' y 'mos' se ha dado en hacer sinónimos los significados de ética y moral (Loiseau, 2002), pero cabe destacar que, esto no ha sido del todo aceptado y se plantea si ambas categorías tienen el mismo significado. Aunque esta cuestión no sea interrogante que trascienda, es importante señalar la diferencia entre ambas al momento de que los profesionales trabajen con estas en la mediación y cuando los mediadores ejercen esta profesión en determinada ideología política y cultural. 
Para (Cortina, 1999) la "moral" es un conjunto de principios, normas y valores que cada generación transmite, en la confianza que se trata de un buen legado de orientaciones sobre el modo de actuar para llevar una vida justa.

Para definir moral con una base que busca encajar en una base social a diferencia de la ética que persigue una conducta individual, pero ambas se refieren a un conjunto de normas a las cuales se debe adaptar el comportamiento humano, tanto desde el punto de vista individual como social y bien podemos decir que la moral es un conjunto de normas que se pasan de generación en generación y la ética es un conjunto de normas que el propio individuo interioriza a forma personal en la cual el mismo decide que es correcto e incorrecto y esta varia de individuo a individuo siendo así subjetiva de acuerdo a criterio de cada quien, para (Loiseau, 2002)La moral se impone desde el exterior, la ética es interior y estas normas morales son propias de grupos étnicos, religiosos por mencionar algunos y estas se van cambiando a lo largo del tiempo adaptándose a las sociedades y a las nuevas corrientes de pensamiento, lo que ocasiona que estas difieran significativamente ya que son muchos factores los que intervienen en el desarrollo de una sociedad, variando ampliamente de un grupo a otro.

Esta diferenciación que se establece entre ética y moral partiendo de lo individual a lo social puede llegar a plantear dilemas en un proceso de mediación, pues las normas sociales pueden llegar en conflicto con la ética de la persona.

En este punto es cuando el mediador debe de decidir cómo actuar, si de acuerdo con la norma social o según su forma individual de actuar, es decir, de acuerdo a sus valores interiorizados sus principios éticos o según las exigencias de la mediación.

\section{LA DIFERENCIA ENTRE ÉTICA PROFESIONAL Y DEONTOLOGÍA}

En este apartado se cuestiona ¿Qué añade la ética profesional a la ética personal? Se podría decir que, la ética profesional es una extensión de la ética, una categoría que se añade. En realidad, la ética profesional continua refiriéndose al mundo de la subjetividad, de los valores interiorizados que se convierten en normas que rigen el comportamiento individual, 
pero que en el caso de los profesionales ensanchan el campo de aplicación a los servicios que prestan a la sociedad para lo cual se les exige haber adquirido saberes y destrezas prácticas. Se trata de la misma ética personal que normaliza lo que es correcto o incorrecto, obligatorio o permitido en una relación social ordinaria, pero añade las dimensiones particulares que plantea la profesión cual segunda naturaleza adquirida (Pantoja Vargas, 2011), es por esto la importancia de los códigos deontológicos para el uso de cualquier profesión no solo la mediación, es necesario saber, conocer e interiorizar los criterios éticos con los cuales cada mediador a de actuar en el proceso.

Para evitar la imprecisión del significado es conveniente remitirse tanto a los orígenes etimológicos como a las tradiciones filosóficas de donde surgen. De acuerdo a (Aznar, 1999),"el término deontología del griego deon quiere decir deber y alude a algo necesario o preceptivo. La deontología profesional se remite al conjunto de códigos, reglas y normas exigibles de forma explícita a todos los que ejercen una misma profesión en un campo social determinado, con la pretensión de regular en forma homogénea las conductas individuales de los agentes que allí participan", es necesario que toda ciencia en particular tenga definidas estas normas para ejercer en las diversas profesiones y que estas normas de conducta y actuación queden claras para todos los individuos que en dicha ciencia participan.

De acuerdo a (Cortina, 1999, pág. 45), "la tradición filosófica de donde procede la ética deontológica o éticas del deber, que surgen de la tradición kantiana, que nos dice; los seres racionales tenemos conciencia de que debemos cumplir deberes, aunque con ello no obtengamos bienestar, sencillamente porque actuar según ellos forma parte de nuestro ideal de humanidad". Podemos reflexionar la ideología Kantiana referente al deber y el querer, indiferentemente de lo que el individuo pueda desear, se ve obligado a cumplir el objetivo que la sociedad persigue, aunque esta no logre su bienestar personal y es compresible que en algunas profesiones se requiera tomar este tipo de posiciones, resulta interesante que los profesionales al conocer las normas éticas de sus profesiones descubran las áreas de oportunidad para trabajar en ellas en caso de no haberlas desarrollado como algo innato.

Para (Etxeberria, 2002), la ética se centrará en señalar en qué consiste la actuación correcta que nos hace personas buenas, y en el caso concreto de la ética profesional, se entiende que el profesional debe en todo momento buscar la excelencia en los servicios que ofrece a la 
sociedad, es por esto la importancia de estos códigos en la actualidad por los contextos y la cultura en la que vivimos, mismos que son necesarios para los profesionales de todas la ciencias no solo de la mediación.

(Bentham, 1834), define por primera vez la deontología en general, como la "ciencia de los deberes o teoría de las normas morales". Entendiendo ahora que esta es aplicada a las profesiones denominada deontología profesional y es la disciplina que se ocupa de determinar y regular el conjunto de responsabilidades éticas y morales que surgen en relación con el ejercicio de la profesión, especialmente aquellas de dimensiones que tienen repercusión social, ahora bien es necesario definir el significado de la ética profesional y a su vez ir señalando sus diferencias para poder clarificar sus conceptos y entender como estas aplican de diferente forma a cada ciencia.

En cambio (Restrepo, 2004, pág. 17) define que la ética profesional es una búsqueda más cercana a la realidad en la que la ética es entendida como un impulso a la excelencia como la decisión individual de hacerse feliz intentando alcanzar esa máxima meta, es decir, que la ética no solo deberá incluir deberes, como en la deontología, sino también, metas, ideales y virtudes, en esta se espera que el procesional actúe de forma consiente, voluntaria y adecuadamente, teniendo en consideración que cada uno reflexione sobre sus fortalezas y competencias al ejercer su profesión, analizando que necesita para ejercer bien su profesión y cuál es su finalidad.

En una sociedad democrática el bien de la profesión se reflejará en la crítica externa de los beneficiarios que reciben el servicio. (Bourdieu, 1990), a través de esta critica la ciencia y el profesional se podrán dar cuenta si sus normas éticas están alineados con la misión de su profesión, por eso la importancia de estos códigos ya que estos reflejan el comportamiento y el desempeño del profesional.

Para resumir, se puede mencionar que deontología solo limita sus actos a través de códigos específicos que demarcar el deber que debe ejercer un profesional cuando brinde su servicio profesional. En cambio, la ética profesional usa el razonamiento y la voluntad, promoviendo la autorrealización y teniendo un proyecto de vida, y que este englobe el beneficio social, en este sentido (Etxeberria, 2002, pág. 30) señala que: “en el ejercicio de las profesiones, 
como en cualquier otra actividad, la moralidad se juega en última instancia en el modo en que las personas concretas, los profesionales en este caso deliberan, deciden y actúan”

\section{LA DEONTOLOGÍA DEL MEDIADOR EN EL PROCEDIMIENTO DE MEDIACIÓN}

La ética y la deontología son esenciales hoy en día para la práctica en cualquier profesión y más en ciencias en las cuales se trata con personas en situaciones sensibles, tal es el caso de la mediación.

Por tanto, es necesario una formación y conocimiento ético y deontológico intencionada a ejercer la profesión y esta formación debería incluir cual es el objetivo de conocer sobre la ética de forma más específica en la mediación, la moral y la deontología.

La ciencia de la mediación necesita valores y, entre ellos deben considerarse los éticos, es importante reflexionar sobre los valores éticos de la mediación como ciencia aplicada y como aplicación de la ciencia para así poder llegar a códigos deontológicos.

Se entiende la mediación como ciencia aplicada, esta no puede quedar reducida al saber de la ciencia y en la práctica deben de quedar bien definidos e identificados los valores éticos que le darán la validez y la confianza que esta requiere, que a su vez permitirá aplicar los criterios que corresponden en casos específicos.

Es necesario tener en cuenta el marco de los valores éticos en la mediación como ciencia aplicada y en aplicación, han de reflejarse en la formación universitaria y en los códigos deontológicos y al no tener claros y entender estos valores éticos, se puede ocasionar confusiones en las formas de actuación de los mediadores al ejercer la práctica profesional.

Debido al creciente desarrollo de la mediación y en consideración a que cada vez se extienda más ante diversos métodos de resolución extrajudicial de conflictos y de acuerdo a la ley de mecanismos alternativos del estado de Nuevo León, que nos dice que se promueve y regula la prestación de mecanismos alternativos de solución de controversias para la prevención 
y, en su caso, la solución de conflictos con excepción de la materia penal. Esto hace que sea necesario e indispensable tener claro los códigos de ética y moral que se aplican a la mediación, pero este conocimiento no es propio de los profesionales que ejercen esta profesión, también para las personas que acudan a estos métodos en búsqueda de solucionar sus controversias.

No solo es necesario el conocimiento científico-técnico, si no el acercamiento a la humanidad. En esta aproximación no basta la competencia profesional, sino las disposiciones necesarias para ser una buena persona, un buen profesional (Moreno Villares, 2014).

En este sentido Texto dirigido para el Programa de Capacitación Integral del Perfil Especialista en Métodos Alternos de la SEGOB en 2015, en su contenido nos data de puntos referentes a la ética profesional del mediador y de cómo la ética profesional del mediador en conjunto con las virtudes y valores sirven de guía para la conducta en los procesos en los cual este participe.

De acuerdo al Programa de capacitación integral los principios y valores éticos en el desempeño profesional es la tarea más ardua en la transformación en el sistema procesal que conlleva al cambio cultural con respecto a conductas en el desempeño de la responsabilidad. Los Mediadores, Conciliadores, Facilitadores, Jueces, Magistrados, Fiscales, Defensores, Peritos, Policías, Universidades y la sociedad en general, pueden contribuir en la formación de individuos que sean capaces de lograr una metamorfosis cultural en el cambio de la cultura ética. En este sentido, la filosofía y la sociología jurídica deben ponderar los valores éticos de los hombres y mujeres útiles a la realidad nacional; es por esto que no necesariamente a la mediación por ser del orden jurídico se le debe de dar solo ese enfoque, es importante que debido a la naturaleza humana que esta tiene y los puntos tan vulnerables que trata con los seres humanos se desarrolle un enfoque humanista que dote a los mediadores no solo de las herramientas pedagógicas y reglamentarias necesarias para desarrollar su labor, también que se les enseñe la importancia de desarrollar virtudes aportando al sentido humano en pro de su profesión.

El aspecto ético- moral es de importancia relevante en el proceso de formación integral de las personas, ya que de ello dependerá su desarrollo, considerado como la base fundamental de la superación personal y social. 
Es así como programa de capacitación integral del mediador en sus párrafos remarca la importancia de seguir desarrollando herramientas en el mediador que no solo lo hagan un buen profesional, sino que también este sea excelente y lo que marque la diferencia sea ese aspecto moral, ético y virtuoso.

El artículo 5 de la Ley de Mecanismos Alternativos para la Solución de Controversias del Estado De Nuevo León, reformada en junio del 2017, nos dice que los facilitadores de mecanismos alternativos, los empleados de apoyo administrativo de los Centros de Mecanismos Alternativos públicos y privados, los intervinientes y en general toda persona que participe en un mecanismo alternativo deberán observar los siguientes principios, pero es importante analizar si estos principios deontológicos están enfocados a el perfil profesional del mediador o terminan siendo o teniendo el mismo impacto en su definición general, por tanto en la siguiente tabla se presentan los principios de la mediación como los marca la ley y la definición de la ética en general para poder apreciar las diferencias conceptuales, que varían de acuerdo al perfil que el mediador requiere.

\begin{tabular}{|c|c|c|}
\hline Concepto & Definición en la mediación & Definición en la Ética general \\
\hline I.Confidencialidad & $\begin{array}{l}\text { Toda persona debe mantener absoluto sigilo } \\
\text { respecto de la información obtenida durante el } \\
\text { desarrollo de un mecanismo alternativo, debiendo } \\
\text { abstenerse de divulgarla o utilizarla para fines } \\
\text { distintos al método elegido. Lo anterior, salvo } \\
\text { acuerdo en contrario de los participantes en } \\
\text { controversia respecto de éstos, que conste por } \\
\text { escrito, que no contravenga alguna disposición } \\
\text { legal y que no afecte los intereses de terceros, de } \\
\text { menores o incapaces. } \\
\text { El facilitador deberá informar a las partes sobre la } \\
\text { importancia y alcances de la confidencialidad. Este } \\
\text { principio implica además que las sesiones del } \\
\text { mecanismo alternativo de que se trate se celebrarán } \\
\text { en privado }\end{array}$ & $\begin{array}{l}\text { "La confidencialidad se fundamenta en el } \\
\text { derecho a la intimidad, entendido como } \\
\text { un derecho inherente a la persona en un } \\
\text { ámbito en el que los seres humanos } \\
\text { gestionan libremente su mundo de valores } \\
\text { y principios; y es en este contexto en el } \\
\text { que surge el deber de secreto entendido } \\
\text { desde una doble perspectiva, por un lado } \\
\text { como un derecho del usuario a que no se } \\
\text { revele información sensible a otras } \\
\text { personas de la que él es titular, y por el } \\
\text { otro como el deber de sigilo de quien } \\
\text { recibe la confidencia". (Ferro, 2014) }\end{array}$ \\
\hline II. Equidad & $\begin{array}{l}\text { Es la obligación de vigilar por el facilitador que las } \\
\text { partes entiendan claramente los contenidos y } \\
\text { alcances del convenio que hubieren acordado, y de } \\
\text { verificar que no sea contrario a derecho o producto } \\
\text { de información falsa, de una } \\
\text { Decreto Núm. } 183 \text { expedido por la LXXIV } \\
\text { Legislatura } 6 \\
\text { comparecencia de mala fe o de imposible } \\
\text { cumplimiento. Igualmente, cuando el facilitador } \\
\text { detecte desequilibrio entre las partes, procurará, } \\
\text { sobre la base de sus intervenciones, balancear y } \\
\text { equilibrar el procedimiento; }\end{array}$ & $\begin{array}{l}\text { "Se define como un ejercicio deliberativo } \\
\text { normativamente marcado por la igualdad } \\
\text { y en consecuencia por la ética. Una } \\
\text { conducta justa en el diálogo "respeta la } \\
\text { dignidad del otro al igual que la mía, nivel } \\
\text { de justicia que significa igualdad en la } \\
\text { distribución de la estima" (Ricoeur, 2009) }\end{array}$ \\
\hline
\end{tabular}




\begin{tabular}{|c|c|c|}
\hline III. Flexibilidad & $\begin{array}{l}\text { El procedimiento de que se trate evitará sujetarse } \\
\text { al cumplimiento de formas y solemnidades rígidas. } \\
\text { Los facilitadores y las partes tienen la facultad para } \\
\text { convenir la forma en que se desarrollará el } \\
\text { procedimiento respectivo, pudiendo obviar, de ser } \\
\text { necesario, una o más etapas del mismo; }\end{array}$ & $\begin{array}{l}\text { lo que es bueno en sí, no sólo para mí o } \\
\text { para ti, aquí y ahora, sino común a todos } \\
\text { y siempre, a cuya luz será posible } \\
\text { determinar la bondad de las acciones } \\
\text { particulares; y lo buscan racionalmente, a } \\
\text { través del diálogo de uno con otro, como } \\
\text { camino adecuado para hallar } \\
\text { precisamente lo que nos es común y, en } \\
\text { cuanto nos comunica, puede fundar una } \\
\text { comunidad humana (García G., 1997) }\end{array}$ \\
\hline IV. Honestidad & $\begin{array}{l}\text { Es obligación del facilitador excusarse de } \\
\text { participar en un procedimiento por falta de } \\
\text { aptitudes suficientes, o cuando se ubique en alguno } \\
\text { de los supuestos de impedimentos y excusas a que } \\
\text { alude la legislación procesal aplicable al conflicto; }\end{array}$ & $\begin{array}{l}\text { "El concepto Honestidad hace referencia } \\
\text { a un valor propio de la naturaleza humana, } \\
\text { sinónimo de verdad, sinceridad y } \\
\text { transparencia y va más allá de la } \\
\text { concepción de no cometer actos de hurto, } \\
\text { ya que también está asociada a la } \\
\text { preservación de los recursos con los } \\
\text { cuales se lleva a cabo una labor sean } \\
\text { materiales o inmateriales, como, por } \\
\text { ejemplo, el tiempo. Igualmente este autor } \\
\text { considera que persona honesta es "una } \\
\text { persona íntegra, que en su vida no da } \\
\text { cabida a la dualidad, la falsedad, o el } \\
\text { engaño" (Zarate, 2003) }\end{array}$ \\
\hline V. Independencia & $\begin{array}{l}\text { La persona propuesta como facilitador debe dar a } \\
\text { conocer a las partes cualesquiera hechos o } \\
\text { circunstancias susceptibles, desde el punto de vista } \\
\text { de las partes, de poner en duda su independencia, } \\
\text { así como cualquier circunstancia que pudiere dar a } \\
\text { lugar a dudas razonables sobre su imparcialidad. El } \\
\text { facilitador de que se trate será confirmado en su } \\
\text { encargo cuando las declaraciones que haya } \\
\text { manifestado no contengan ninguna reserva } \\
\text { respecto de su imparcialidad e independencia o, si } \\
\text { la contiene, ésta no haya provocado alguna } \\
\text { objeción de las partes; }\end{array}$ & $\begin{array}{l}\text { "La existencia auténtica o propia, por otro } \\
\text { lado, consiste en buscar la realización de } \\
\text { las propias posibilidades como un } \\
\text { individuo solo y como si uno estuviera } \\
\text { aislado y en independencia. También es } \\
\text { tomar plena responsabilidad para } \\
\text { cualquier cosa que se hace. Consiste en } \\
\text { tomar mis compromisos personales como } \\
\text { irreductiblemente propios, a pesar de que } \\
\text { puedan entrar en conflicto, o ser } \\
\text { irreconciliables, con las normas morales } \\
\text { socialmente aceptadas que se aplican a } \\
\text { todos, yo incluido. (Hegel, 1988) }\end{array}$ \\
\hline VI. Imparcialidad & $\begin{array}{l}\text { El facilitador debe contener sus impulsos naturales } \\
\text { de simpatía, agrado o concordancia con } \\
\text { determinadas ideas, situaciones o partes que se } \\
\text { encuentren involucradas en un mecanismo } \\
\text { alternativo. Asimismo, el facilitador deberá evitar } \\
\text { situaciones que le generen dependencia entre él y } \\
\text { las partes que pueda o que al menos parezca que } \\
\text { pueda, afecte la libertad del facilitador para } \\
\text { desempeñar su encargo. Así las partes reciben el } \\
\text { mismo trato y pueden percibir que el facilitador es } \\
\text { una persona libre de favoritismos respecto de su } \\
\text { controversia, que ha asumido el compromiso de } \\
\text { apoyarlos por igual, sin propiciar ventajas para una } \\
\text { u otra parte; }\end{array}$ & $\begin{array}{l}\text { "Se define la imparcialidad como el hecho } \\
\text { de que los individuos, en la medida en que } \\
\text { están interesados en las relaciones de } \\
\text { intercambio y cooperación con los demás, } \\
\text { concuerdan también en el interés de } \\
\text { mantener un sistema de reglas cuya } \\
\text { aplicación cuente con su asentimiento, } \\
\text { siempre que también todos los demás se } \\
\text { sometan al mismo tiempo a ellas" } \\
\text { (Gauthier, 1994) }\end{array}$ \\
\hline VII. Neutralidad & $\begin{array}{l}\text { Es la obligación del facilitador para abstenerse de } \\
\text { emitir juicios u opiniones que puedan influir en las } \\
\text { conclusiones a que arriben las partes, con }\end{array}$ & $\begin{array}{l}\text { "La neutralidad desde la perspectiva } \\
\text { moral, al respecto de cualquier hombre } \\
\text { ciudadano calificado en alguna rama del }\end{array}$ \\
\hline
\end{tabular}




\begin{tabular}{|l|l|l|}
\hline & $\begin{array}{l}\text { excepción del procedimiento de conciliación y de } \\
\text { aquellos casos en los que éste advierta la existencia } \\
\text { de posibles hechos delictivos o de violencia } \\
\text { familiar, en cuyo caso deberá dar por terminado el } \\
\text { procedimiento correspondiente, tomando las } \\
\text { medidas que sean necesarias para proteger la } \\
\text { integridad física y emocional de los participantes }\end{array}$ & $\begin{array}{l}\text { saber lo dota para conocer los posibles } \\
\text { esponsabilidad moral de informal el mal } \\
\text { uso que de ella se puede hacer". (Nuñez, } \\
1994)\end{array}$ \\
\hline VIII. Voluntariedad & $\begin{array}{l}\text { Las partes deberán estar libres de presión alguna } \\
\text { para acudir, permanecer o retirarse del mecanismo } \\
\text { alternativo de que se trate; aportar la }\end{array}$ & $\begin{array}{l}\text { "Es la acción humana que procede de un } \\
\text { acto libre y voluntario. Por tanto se } \\
\text { excluyen los actos meramente naturales, } \\
\text { Legislatura 7 183 expedido por la LXXIV }\end{array}$ \\
$\begin{array}{l}\text { los coaccionados y los no imputables". } \\
\text { información que consideren pertinente; así como } \\
\text { decidir si llegan o no a un convenio, elaborado por } \\
\text { ellos mismos. }\end{array}$ & \\
\hline
\end{tabular}

Todo facilitador, al momento de aceptar dicho encargo, deberá suscribir una declaración donde manifieste su adhesión y cumplimiento a los principios señalados en este artículo

El reto para la mediación implica que los servidores públicos y profesionales que se dediquen a esto no solo cuenten con las herramientas técnicas y específicas, lo que suma al profesional es el desarrollo de una ética profesional, de valores, cualidades, virtudes y buenas actitudes de comportamiento humano que permitan un mejor desarrollo en su profesión, teniendo como valor agregado el desarrollo humanista al cual no se le da la importancia que requiere.

La finalidad de las normas de conducta éticas con los intervinientes en un proceso de mediación debe asegurar que estos comportamientos en relación con las partes intervinientes se conducirán con principios de confidencialidad, equidad, flexibilidad, honestidad, independencia, imparcialidad, neutralidad y voluntariedad, de acuerdo a la ley de mecanismos alternativos del estado de Nuevo León. Los mediadores no solo deben obedecer a la Ley si no también a la moral y si no cumplieran estos principios serán sancionados y esto afectaría de manera directa en la mediación como proceso de solución de conflictos y en la calidad de este servicio.

Por tanto, es necesario que el mediador, como profesional que presta servicios, disponga y cumpla de un código de ética que cubra las necesidades del proceso a seguir para evitar malas 
prácticas en su ejercicio profesional y tenga claro conceptos básicos como moral y ética y como estas aplican en su trabajo diario, con la finalidad de brindar mejores servicios.

Es necesario señalar la importancia de la existencia de un Código Deontológico que rija la mediación, para concientizar al mediador, aunque en principio sea complica por la multidisciplinariedad que caracteriza a esta figura y es por ello que esto debe ser el punto de partida por la cual debe de especificarse la función del mediador en las prácticas profesionales

Cualquier profesión plantea problemas éticos susceptibles de distintas soluciones, la implicación ética de los profesionales de la mediación es indispensable para que el mediador pueda ejercer su profesión de la mejor manera, dotado del conocimiento necesario no solo técnico ni científico, también el lado humano y sin estos principios difícilmente el mediador podrá alcanzar un grado de ética elevado.

\section{LAS VIRTUDES CÍVICAS COMO NECESIDAD FORMATIVA}

En este apartado se comenzará explicando el concepto de virtud cívica, es necesaria la comprensión de esta definición y cuál es la relación con el proceso de mediación y con el facilitador. Cabe destacar que este no es un tema para nada nuevo y es de los conceptos más recurrentes en el área de las ciencias sociales y la filosofía, pero es necesario que en la actualidad no quede mal comprendido sobre todo si este es el pilar que construye un buen profesional en la mediación.

Si bien, es necesario destacar que a pesar que ya otros pensadores filosóficos como Aristóteles, Platón, Sócrates y Kant, hablaban de virtudes, por mencionar algunos de los pensadores más destacados de los que hablará más adelante, estos dan su definición y operativización del concepto de virtud según convenga a sus fines, el contexto social en el que se desarrolló y su significado particular de la misma.

No obstante, desde el punto de vista de una ciencia social, como lo son los mecanismos alternativos de solución de conflictos, la ausencia y el desconocimiento en función de una 
definición y uso preciso, supone limitantes para el trabajo del profesional, precisamente porque no se su importancia y no se desarrollan, y son las instituciones tanto públicas, privadas o que brinden un servicio las que deben partir de este pilar, entendiendo así su finalidad, alcances y herramientas necesarias, como parte fundamental que se trabaje en el desarrollo humano interiorizando los valores, virtudes, códigos de ética que aporten al perfil profesional, identificando así las virtudes que se necesitan o que están ausentes, el profesional no solo habrá alcanzado un conocimiento práctico, también el interno, desarrollando y conociendo otros aspectos que contribuyen a su desarrollo personal y el colectivo.

En este capítulo se plantea explicar con precisión que es virtud cívica, de acuerdo a las fuentes que se consultaron, teniendo claro que estas conceptualizaciones serán aplicadas para una rama del saber en específico, los Mecanismos Alternativos para la Solución de Controversias, proponiendo algunas virtudes cívicas básicas que pueden iniciar como punto de partida en las virtudes que requiere el mediador, pero es necesario señalar que el desarrollar virtudes cívicas es aplicable para cualquier ciencia social, ya que identificar estas, nos ayuda a saber cuáles son necesarias para cada área del conocimiento y este es el pilar para formar excelentes profesionales e instituciones que sean conscientes que lo principal es desarrollar en su es su personal herramientas que les permitan hacer mejor su trabajo y además en lo interno, porque ellos son los que estarán brindando su profesión de la mejor manera.

Para entender mejor este concepto se describirá virtud cívica como la motivación causalmente eficiente para la acción públicamente orientada (Tena Sánchez, 2010), con el fin de que esta definición sea lo más clara posible, se comenzara explicando la virtud cívica como un tipo de motivación, después se analizará la otra parte que es lo socialmente orientado y que tipo de motivaciones constituyen la virtud, posterior a esto se explicara la diferencia de motivación virtuosa y acción correcta, ¿Que es la extensión social de la virtud? y se concluirá en saber cuál es la relación y virtudes que contribuyen con los mecanismos alternativos de solución de conflictos y mediador. 


\section{COMPONENTES DE UNA VIRTUD CÍVICA}

La civic virtue o public spiritedness, según la denominaban los humanistas cívicos ingleses (Ovejero, Martí y Gargarella, 2004: 24), tenía una doble dimensión: por un lado, requería de la capacidad para discernir lo que el bien público requiere, y, por el otro, exigía la motivación para actuar según sus dictados (Brennan y Hamlin, 1995: 37). De acuerdo a la definición de los ya mencionados, podríamos decir que la virtud cívica en términos de ciencias sociales, parte de dos dimensiones una cognitiva, que nos permite usar el pensamiento lógico y discernir en hacer lo políticamente correcto y una motivacional que parte de nuestros deseos, que no necesariamente pueden ser correctamente orientados a lo público. Estas conceptualizaciones de virtud cívica para los humanistas no represento algo novedoso en referencia a la definición del concepto, pero contrapone muchas de las definiciones anteriores y apoya muchas de las contemporáneas. Para Platón y Aristóteles el desarrollo de virtudes requería de sabiduría y de un profundo conocimiento de uno mismo, lo que mencionan como un bien supremo, lo que considero fundamental para el desarrollo interno e individual, pero para ambos autores las dificultades para ver con claridad el fin supremo representaban el mayor obstáculo que podía interponerse en el camino de los hombres, hacia la actualización de su ser (Domènech, 1989: 78 y ss) y si bien tiene razón, es necesario saber que si se le sigue restando importancia al desarrollo de virtudes difícilmente se llegara a progresar en este ámbito tan importante que es la humanización de los valores y que estas aportan no solo al individuo que las desarrolla, también de forma colectiva y como menciona (Herreros, 2002: 26), No se trataba sólo de que la virtud tuviese dos dimensiones, sino que no existía diferencia alguna entre lo que en lenguaje moderno denominaríamos el bien privado y el público.

Xunci, caracterizó las virtudes como disposiciones que envuelven las facultades de elección, juicio, deseo y acción (Benkler y Nissenbaum, 2006: 405), Por tanto, se plantea importante que el profesional entienda que, el procesar una virtud requiere de un proceso cognitivo y emocional y el poder tener los dos en equilibrio requiere de hacer un análisis profundo para actuar a consciencia y obrando de la mejor manera, en este sentido podemos ver como el enfoque de las virtudes va cambiando, ya no solo es una cuestión en la que un individuo 
actúa por y de buena fe, cuando hablamos de virtud cívica hablamos de un estado consciente de la mente que nos permite hacer un juicio orientado a un beneficio social.

Tal como menciona R. Putnam (2000:102) al virtuoso ilustrado no se le pide que no sea egoísta, se le pide más bien que sea perfectamente racional, que persiga su propio interés bien entendido, lo que en otras cosas requiere es saber discernir entre el interés propio y no sucumbir al interés cortoplacista, como se puede apreciar la virtud cívica no es una cuestión solo de hacer las cosas bien en función de lo que uno piensa que es correcto o no, en este sentido el mediador está orientado a actuar en función de las virtudes, sin poner en duda que se promueven los intereses de los mediados antes que los propios.

Ahora bien, entendiendo como interactúan las virtudes cívicas, cognitivamente a través de elección, juicio, deseo y acción, es necesario conocer los escenarios para actuar en función de las virtudes cívicas, la primera que nos dice que discernir lo que la virtud cívica requiere de nosotros no implica estar motivados para actuar según dicho requerimiento (Nagel, 1991; Noguera, 2003: 18) Es decir la forma en que se interiorizan estos virtudes dejan muy claro que el profesional debe actuar si o si confirme a ellas, pero esto solo se hace desde la mente consciente, aprendiendo a diferenciar cual es el interés propio y el colectivo, por eso es la importancia de entender como está compuesta, para entenderla y aplicarla responsablemente como profesionales.

\section{MOTIVACIÓN Y DISPOSICIÓN QUE CONSTITUYEN UNA VIRTUD CÍVICA}

Ahora se entiende que la virtud tiene un lado cognitivo, pero esta se compone de más elementos, se pone de manifiesto tres cuestiones referentes que es lo que conforma motivacionalmente una virtud, ¿Si son cuestiones inherentes al carácter del individuo?, ¿Son las motivaciones del mismo lo que logra que esta se logre? ¿O las motivaciones concretas que se esconden tras una acción virtuosa específica?, para responder a la primer pregunta podemos decir que, tenemos que analizar que no todos los individuos nacen con estas, es por eso la importancia de ser consciente que en la profesión se requiere ciertas habilidades y es necesario 
tener en cuenta que debido a la educación y contextos en los cuales crecen las personas, por otro lado debes ser tomados en cuenta, para el desarrollo de cualquier profesional no solo en el contexto de los MASC, o aprenden en algún punto específico de e podemos decir que algunas personas habrán de nacer con alguna de las virtudes o las habrán adquirido con el aprendizaje para entender mejor esto podemos decir que muchas veces decimos que una persona es prudente, mientras que en otras ocasiones usamos ese mismo término para una acción en concreto, en el segundo caso podemos ver que un determinado acto se ha llevado de forma prudente y la verdad de este acto es que se llevó a cabo independiente de las motivaciones de la persona que lo realizo.

Un punto de vista disposicional toma el uso global como el constitutivo de la virtud cívica y, en mayor o menor medida, concibe los actos, deseos o sentimientos virtuosos como aquellos que se derivan de un carácter virtuoso (Hurka, 2006: 69-70), en lo que refiere a esta opinión se puede contrastar con la información ya antes presentada, que este punto de vista coincide mayoritariamente entre los filósofos. Ya Aristóteles sostenía que para poder considerar que un acto es virtuoso éste debe proceder de un carácter firme e incambiable (1980: 1105a31b12). En este caso continuado con el ejemplo anterior si un acto prudente es llevado acabo por una persona carente de virtud, podemos decir que es un acto prudente o incluso un acto que una persona virtuosa realizaría, pero no se podría decir que se tratase de un acto virtuoso. La misma concepción, aunque tal vez en formulaciones menos extremas, se encuentra también tras la virtus del más laureado de los filósofos romanos, Cicerón (Ovejero, Martí y Gargarella, 2004: 23 y ss., Skinner, 2004: 104 y ss.) Lo mismo sucede con la virtù de los teóricos italianos posteriores (Ovejero, Martí y Gargarella, 2004: 23) o la civic virtue de los humanistas cívicos ingleses (Brennan y Hamlin, 1995: 37). Estos filósofos coinciden que la virtud cívica son capacidades que se deben poseer como ciudadano con el fin de poder servir a la sociedad con voluntad propia, siendo el valor y la prudencia las más importantes de estas capacidades. Es por ello fundamental entender la diferencia entre las virtudes y las virtudes cívicas, porque cada una tiene sus componentes que en algún punto son coincidentes pero las motivaciones y los trasfondos van cambiado dependiendo del enfoque que se le dé a cada una de ellas y estos enfoques ayudan a los profesionales como herramientas para desarrollar su trabajo no solo de forma profesional, también de manera personal, como ya lo mencionaba Xunzi, están dan facultades de elección, juicio, deseo y acción, que contribuyen a que los mediadores lleven su trabajo lo mejor posible, desde un enfoque personal y profesional. 
Poniendo en contraste la perspectiva motivacional tal como lo define (Hurka, 2006; Ross, 19304) las motivaciones detrás de las acciones concretas las que constituyen la virtud y desde este punto de vista, solo podemos hablar de disposiciones, caracteres o personas virtuosas desde un panorama derivado.

\section{VIRTUDES QUE CONTRIBUYEN A LOS MECANISMOS ALTERNATIVOS DE SOLUCIÓN DE CONFLICTOS Y COMO APORTAN EN EL PROCESO DE MEDIACIÓN}

Finalmente, las virtudes que se proponen como las adecuadas para que los mediadores las desarrollen para el ejercicio laboral son:

\begin{tabular}{|c|c|c|}
\hline VIRTUD & CONCEPTO DE VIRTUD & $\begin{array}{lcccc}\text { FORMA } & \text { EN } & \text { QUE } & \text { PUEDE } & \text { SE } \\
\text { UTILIZADO } & \text { EN } & \text { EL } & \text { PROCESO } & \text { DE } \\
\text { MEDIACIÓN } & & & & \\
\end{array}$ \\
\hline PRUDENCIA & $\begin{array}{l}\text { Consiste en actuar o hablar con cuidado, } \\
\text { de forma justa y adecuada, con cautela, } \\
\text { con moderación, con previsión y } \\
\text { reflexión, con sensatez y con } \\
\text { precaución para evitar posibles daños, } \\
\text { dificultades, males e inconvenientes, y } \\
\text { respetar la vida, los sentimientos y las } \\
\text { libertades de los demás. }\end{array}$ & $\begin{array}{l}\text { 1. El mediador ha de ser precavido en su } \\
\text { conducta en el proceso. } \\
\text { 2. El mediador ha de actuar con cautela en } \\
\text { el proceso. } \\
\text { 3. El mediador ha de ser moderado en sus } \\
\text { opiniones para con los mediados. }\end{array}$ \\
\hline TOLERANCIA & $\begin{array}{l}\text { Es el reconocimiento de las diferencias } \\
\text { inherentes a la naturaleza humana, a la } \\
\text { diversidad de las culturas, las religiones o } \\
\text { las maneras de ser o de actuar, } \\
\text { independientemente de que choquen o } \\
\text { sean diferentes a las de cada individuo. }\end{array}$ & $\begin{array}{l}\text { 1. El mediador reconoce la individualidad } \\
\text { de cada ser humano } \\
\text { 2. El mediador ha de entender que existen } \\
\text { maneras de pensar diferentes a las suyas } \\
\text { 3.El mediador puede aceptar opiniones o } \\
\text { comportamientos diferentes a los } \\
\text { establecidos }\end{array}$ \\
\hline TEMPLANZA & $\begin{array}{l}\text { Consiste en actuar o hablar de forma } \\
\text { cautelosa y justa, con sobriedad, con } \\
\text { moderación o continencia para evitar } \\
\text { daños, dificultades e inconvenientes, } \\
\text { teniendo control de emociones o } \\
\text { impulsos. }\end{array}$ & $\begin{array}{l}\text { 1. El mediado reacciona de manera } \\
\text { equilibrada ante situaciones de conflicto } \\
\text { 2. El mediador tiene control sobre sus } \\
\text { emociones en los procesos } \\
\text { 3.El mediador es racional en cada una de sus } \\
\text { acciones dentro del proceso }\end{array}$ \\
\hline PACIENCIA & $\begin{array}{l}\text { Capacidad del mediador de sobreponerse } \\
\text { a las emociones fuertes o intensas de los } \\
\text { mediados }\end{array}$ & $\begin{array}{l}\text { 1. Mantiene calma durante el proceso } \\
\text { 2. Respeta el tiempo previsto en las etapas } \\
\text { del proceso } \\
\text { 3.Comprende que las partes tienen } \\
\text { emociones que expresan durante el proceso } \\
\text { y no le afecta }\end{array}$ \\
\hline
\end{tabular}




\section{BIBLIOGRAFÍA}

Campos, j. (1988). Bolivar. Barcelona: Salvat Editores, S.A.

Lindsay, G. (2009). ÉTICA PROFESIONAL Y PSICOLOGÍA. Papeles del Psicólogo.

Loiseau, P. M. (2002). Modelos teóricos de las éticas profesionales. Ética y calidad universidad de Barcelona, 161-175.

Cortina, A. (1999). El quehacer ético. Guía para la educación moral. Madrid: Santillana.

López de Llergo, A. T. (2000). Valores, valoraciones y virtudes. México: Compañía Continental.

García, D. (1980). El puesto de la razón en la ética. Barcelona: CONFORD.

Ramos Montes, J. (2018). Ética y salud mental. Barcelona: Herder.

Aranguren, J. L. (2013). Ética y política. Biblioteca nueva.

Aristóteles. (1984). Ética Nicomaquea. México: Porrúa.

Aznar, H. (1999). Comunicación reponsable. Deontología y autorregulación de los medios. Barcelona: Ariel.

Bentham, J. (1834). Deontología ó ciencia de la moral. Valencia: Mallén y Sobrinos.

Bentham, J. (2010). Un fragmento sobre el gobierno. Tecnos.

Bilbeny, N. (1992). Ética para la vida: razones y pasiones. Barcelona: Península.

Bourdieu, P. (1990). Sociología y cultura. México: Grijalbo.

Burlando, G. (2012). Historia de la virtud que buscamos: del aristotelismo a la modernidad. Acta Scientiarum. Education.

De la Cruz, F. J. (2000). Ética y Deontología Jurídica. DYKINSON.

Dewey, J. (1899). “The school and society”. Southern Illinois: Middle works of J. Carbondale.

Echegoyen Olleta, J. (2005). Filosofía Medieval y Moderna. Historia de la Filosofía.

Etxeberria, X. (2002). Ética de las profesiones. Bilbao: Declée de Brouwer. 
Fernández, S. P. (2002). Heidegger y la Etica. Crítica a la Metafísica y Nacional-Socialismo. Cinta de Moebio.

Ferro, B. (2014). LA ÉTICA DE LA CONFIDENCIALIDAD EN LA PRÁCTICA. Escuela Universitaria de Trabajo Social.

Filgueiras Nodar, J. M. (2017). La primera ética de Jean-Paul Sartre. Ciencia y Mar.

Fischer, J., \& Orme, J. G. (2003). Ethics a foundation competency. Connecticut: Pearson.

García , G. (1997). El bien y lo recto en Aristóteles. Madrid: Historia de la filosofía antigua, Trotta.

García. (1980). La filosofía como curación por la palabra. España: Contrastes internacional de filosofía.

Gauthier, D. (1994). La moral por acuerdo. Barcelona: Tugendha.

Gurria Dibella, M. (1996). Ética profesional. El turismo como ejemplo. México: Universidad Externado de Colombia, Facultad de Administración de Empresas Turísticas y Hoteleras.

Hartmann, N. (2011). Ética (Ensayo). Ediciones Encuentro, S.A.

Hegel, G. (1988). Principios de la filosofía del derecho. Barcelona: Edhasa.

Kant, I. (1993). La metafísica de las costumbres. Barcelona: Altaya.

Moore, G. E. (2002). Prólogo a la segunda edición de los Principia Ethica. Revista de filosofía.

Moreno Villares, J. M. (2014). Prudencia, virtud indispensable. Cuadernos de Bioética, 105110 .

Naranjo Boza, N. (2004). Sobre las virtudes y los vicios de aristóteles. Revista Lasallista de Investigación.

Nuñez, J. (1994). La etica y la vida. Madrid: CESMA.

Ortiz Millán, G. (2016). Sobre la distinción entre ética y moral. Isonomía.

Pantoja Vargas, L. (2011). Deontología y código deontológico. Pedagogía Social. Revista Interuniversitaria.

Parker Green, C. (2001). Ética, democracia y desarrollo. Santiago: Lom ediciones.

Pellegrino, E. D., \& Thomasma, D. C. (1993). The virtues in medical practice. New york: Oxford University Press. 
Restrepo, J. D. (2004). El zumbido y el moscardón. Taller y consultorio de ética. México: Taller y consultorio de ética.

Ricoeur, P. (2009). Amor y justicia. México: Siglo XXI. México: Trotta, S.A. .

Rodriguez Luño, Á. (2001). Ética general. Pamplona: EUNSA.

Rodríguez, J. (1998). Ética. México: Addison Wesley.

Rodríguez; Lozano. (1998). ETICA 1 ETICA Y MORAL PERSONAL. Madrid: PEARSON EDUCACION.

Sanabria, J. R. (1984). Ética. México: Porrúa.

Steel Garza, J. G. (2015). El código de ética del mediador y su impacto social. En F. Gorjon, La ciencia de la mediación (pág. 225). Distrito Federal, México: Tirant lo blanch.

Tena Sánchez, J. (2010). Hacia una definición de la virtud cívica . Convergencia.

Vidal Gual, M. J. (2006). Las virtudes en la medicina clínica. Archivos en Medicina Familiar, 41-52.

Data de Submissão: 13/03/2020

Data de Aceite: 16/04/2020 